\title{
Prevalence, Antibiogram and Genetic Characterization of Listeria monocytogenes from Food Products in Egypt
}

\author{
Eman E. Abdeen 1,*, Walid S. Mousa ${ }^{2}$, Ola. H. Harb ${ }^{3}$, Gehad A. Fath-Elbab ${ }^{4}$, Mohammed Nooruzzaman ${ }^{5}$ (D), \\ Ahmed Gaber 6,7 (D), Walaa F. Alsanie ${ }^{7,8}$ and Ahmed Abdeen ${ }^{9,10}$ (D)
}

Citation: Abdeen, E.E.; Mousa, W.S.; Harb, O.H.; Fath-Elbab, G.A.; Nooruzzaman, M.; Gaber, A.; Alsanie, W.F.; Abdeen, A. Prevalence, Antibiogram and Genetic

Characterization of Listeria monocytogenes from Food Products in Egypt. Foods 2021, 10, 1381. https:// doi.org/10.3390/foods10061381

\section{Academic Editors:}

Fernando Pérez-Rodriguez and Araceli Bolívar

Received: 3 June 2021

Accepted: 9 June 2021

Published: 15 June 2021

Publisher's Note: MDPI stays neutral with regard to jurisdictional claims in published maps and institutional affiliations.

Copyright: (c) 2021 by the authors. Licensee MDPI, Basel, Switzerland. This article is an open access article distributed under the terms and conditions of the Creative Commons Attribution (CC BY) license (https:// creativecommons.org/licenses/by/ $4.0 /)$.
1 Department of Bacteriology, Mycology and Immunology, Faculty of Veterinary Medicine, University of Sadat City, Sadat City 32897, Egypt

2 Department of Animal Medicine and Infectious Diseases, Faculty of Veterinary Medicine, University of Sadat City, Sadat City 32897, Egypt; walid.saad@vet.usc.edu.eg

3 Faculty of Veterinary Medicine, Veterinarian Teaching Hospital, University of Sadat City, Sadat City 32897, Egypt; ola.harb1373@vet.usc.edu.eg

4 Animal Health Research Institute (AHRI)—Dokki, Giza 12618, Egypt; gehadfathy172@gmail.com

5 Department of Pathology, Faculty of Veterinary Science, Bangladesh Agricultural University, Mymensingh 2202, Bangladesh; mohammed.nooruzzaman@bau.edu.bd

6 Department of Biology, College of Science, Taif University, P.O. Box 11099, Taif 21944, Saudi Arabia; a.gaber@tu.edu.sa

7 Center of Biomedical Sciences Research (CBSR), Taif University, P.O. Box 11099, Taif 21944, Saudi Arabia; w.alsanie@tu.edu.sa

8 Department of Clinical Laboratories Sciences, The Faculty of Applied Medical Sciences, Taif University, P.O. Box 11099, Taif 21944, Saudi Arabia

9 Center of Excellence for Screening of Environmental Contaminants, Benha University, Toukh 13736, Egypt; ahmed.abdeen@fvtm.bu.edu.eg

10 Department of Forensic Medicine and Toxicology, Faculty of Veterinary Medicine, Benha University, Toukh 13736, Egypt

* Correspondence: eman.abdeen@vet.usc.edu.eg; Tel.: +20-100-1346-035

Abstract: World Health Organization classified Listeria monocytogenes as a major notable foodborne pathogen associated with high mortality and hospitalization. The study reports the prevalence, antibiogram, virulence determination and genetic characterization of L. monocytogenes from different food products. A total of 250 food samples, fifty samples each from raw milk, ice cream, minced meat, fish fillet and sausage were collected from the Menoufiya governorate in Egypt. L. monocytogenes was detected in $17(6.8 \%)$ of the tested food samples including minced meat (14\%), fish fillet (8\%), sausage $(6 \%)$ and raw milk $(6 \%)$. The antimicrobial susceptibility assay of 17 L. monocytogenes isolates against seventeen antibiotics belonging to eight antibiotics classes revealed a high susceptibility to norfloxacin $(82.3 \%)$, amoxicillin-clavulanic acid $(76.4 \%)$, cefotaxime $(70.5 \%)$, erythromycin $(64.6 \%)$, amoxicillin $(64.6 \%)$, gentamicin $(58.7 \%)$ and vancomycin $(58.7 \%)$. While, high resistance was observed against oxytetracycline $(76.4 \%)$, trimethoprim-sulfamethoxazole $(76.4 \%)$, chloramphenicol $(70.5 \%)$, doxycycline (64.6\%), levofloxacin (41.2\%) and azithromycin $(41.2 \%)$. Of note, all L. monocytogenes isolates were multidrug-resistant. The multiplex PCR successfully amplified L. monocytogenes in all tested isolates. Screening of the five virulence-related genes revealed the $h l y A$ and iap as the most prevalent genes followed by act $A$ gene, however, the inl $A$ and $\operatorname{prf} A$ genes were not detected in any of the studied isolates. The partial $16 S r R N A$ gene sequencing of three L. monocytogenes isolates showed a high nucleotide similarity (99.1-99.8\%) between the study isolates and various global clones, and phylogenetic analysis clustered these L. monocytogenes strains with other Listeria species including L. welshimeri, L. seeligeri and L. innocua. This study demonstrates the impact of L. monocytogenes as a major contaminant of various food products and suggests more attention to the awareness and hygienic measures in the food industry.

Keywords: L. monocytogenes; virulence genes; foods; sequencing; antibiogram 


\section{Introduction}

Listeria monocytogenes is a ubiquitous foodborne pathogen associated with high hospitalization and outbreaks of food-borne illness worldwide [1]. L. monocytogenes causes listeriosis in humans and animals and can be found in varieties of foods and dairy products [2]. The bacteria is also considered as a potential contaminant source for chilled and marine food products [3] and unpasteurized dairy products and has been detected in recent outbreaks and sporadic cases of listeriosis [4]. In a dairy herd, contaminated teat cups often serve as a potential source in the transmission of L. monocytogenes [2]. In line with this, three L. monocytogenes variant clones, the hypervirulent clones Clonal Complexes 1 (CC1) and hypovirulent clones (CC9 and CC121), were reported in humans that were closely associated with the dairy and meat products, respectively [5].

The pathogenicity of L. monocytogenes is largely determined by a group of virulence genes. L. monocytogenes strains from dairy herds carried a number of virulence markers including the Listeria pathogenicity islands (LIPI) 3 and LIPI-4 that were associated with severe human infections [4]. Virulence factors are associated with crucial stages of adhesion, invasion, reproduction, motility and intercellular spread into host cells and therefore play a key role in virulence and resistance against host immunity [6]. The major determinant virulence genes include internalins encoded by inlA, inlC and inlJ genes, listeriolysin encoded by $h l y A$ gene, actin encoded by act $A$ gene and the invasion associated protein encoded by iap gene [7]. The $h l y A, p l c B$ and prfA virulence genes have been found in L. monocytogenes strains recovered from blood and milk isolates [2]. Furthermore, the prfA virulence gene is a transcriptional activator identified among pathogenic L. monocytogenes [8]. Moreover, biofilm activity is commonly associated with L. monocytogenes of milk origin that carry a variety of virulence and antibiotics resistance genes [2]. Traditionally, Listeria diagnosis is primarily based on isolation and biochemical characterization, which is time consuming. Molecular approaches such as PCR and multiplex PCR (mPCR) provide rapid and specific techniques for the diagnosis of L. monocytogenes targeting specific genes [9].

Antimicrobial resistance is an important public health issue and one of the highest priorities of the World Health Organization (WHO). The growing level of antimicrobial resistance has led to higher patient morbidity and mortality rates and increased healthcare expenditure over the last decades $[10,11]$. The multidrug-resistant $L$. monocytogenes particularly in ready-to-eat foods is being considered as a public health indicator especially among the high-risk groups. It is highly recommended to build awareness about the importance of food safety regulations as well as drugs used in humans and animals [12]. The nucleotide sequence analysis of L. monocytogenes is an effective modern tool for genotyping and analysis of the relatedness of Listeria species with other local or global lineages. A surveillance study conducted in the United States reported a substantial genetic similarity between L. monocytogenes strains from milk tanks with virulent strains isolated from dairy products, which were associated with the outbreaks of food-borne illness in humans [4].

The Menoufiya governorate of Egypt is a densely populated rural governorate where people consume many famous and popular ready-to-eat foods such as minced meat meal, fish dishes, milk products and ice cream. Such raw uncooked or undercooked foods can be a potential source of pathogenic L. monocytogenes in humans. This study describes the virulence and antibiotic resistance profiles of L. monocytogenes detected in various readyto-eat food products from Egypt. In addition, partial nucleotide sequence analysis of the $16 S$ rRNA gene of three L. monocytogenes isolates was performed to correlate the genetic similarities between the study isolates and various global clones having potential public health implications.

\section{Materials and Methods}

\subsection{Ethics Statement}

This study followed the guidelines of the Ethics Committee and current legislation on research and ethical approval of the Faculty of Veterinary Medicine (Local ethical approval), University of Sadat City, Egypt. 


\subsection{Study Area}

This study was carried out in the Monufiya governorate in Lower Egypt. The majority of residents in this governorate live in rural areas, with an urbanization rate of only $20.6 \%$ [13]. The area has a high population density and people consume a lot of ready-toeat popular foods such as minced meat, fish dishes, raw milk products and ice cream.

\subsection{Samples Collection and Processing}

A total of 250 food products ( 50 samples each from raw milk, ice cream, minced meat from beef, fish fillet and sausage) were collected from different local markets at Menoufiya governorate in Egypt from January to August 2020. Each sample was collected separately in a sterile plastic bag and transferred to the laboratory in cooled condition.

\subsection{Phenotypic Isolation and Identification of Listeria from Food Products}

Twenty-five grams of food sample was homogenized with $9 \mathrm{~mL}$ of nutrient broth using a blender. The harvested homogenate was firstly pre-enriched in $225 \mathrm{~mL}$ of Buffered Listeria Enrichment Broth with pyruvate and incubated at $30^{\circ} \mathrm{C}$ for $48 \mathrm{~h}$, then cultured in specific Oxford medium, CHROM agar and sheep blood agar (Himedia, India) for $48 \mathrm{~h}$ at $35^{\circ} \mathrm{C}$ as described by FDA BAM and ISO 11290 method [14]. Characteristic colonies of L. monocytogenes were identified on different agar media. Morphological and biochemical characteristics of the bacteria were analyzed using Gram staining, catalase test, sugar fermentation test and motility test according to FDA BAM and ISO 11290 method [14]. The CAMP (Christie-Atkins-Munch-Peterson) test was performed as described previously [15] using standard hemolytic Staphylococcus aureus strain (MT211620), which was streaked on blood agar in a straight line across the center of the plate, then the L. monocytogenes strain was streaked in a direction perpendicular or vertical to $S$. aureus without touching the $S$. aureus culture. Then the plates were incubated at $37^{\circ} \mathrm{C}$ for $18-24 \mathrm{~h}$ and checked for $\beta$-hemolysis which appeared as an arrowhead, circle or rectangle shape in CAMPpositive species.

\subsection{Antibiogram Profile of L. monocytogenes Isolates Recovered from Food Products}

The Kirby-Bauer disk diffusion method was used to analyze the antibiogram profile of L. monocytogenes isolates. The bacterial suspension was adjusted to a $0.5 \mathrm{McF}$ arland. Seventeen different antibiotic disks (Oxoid Ltd., Basingstoke, UK) belonging to eight different antibiotic groups were used. The antibiotics included amikacin (AK) $30 \mu \mathrm{g}$, ciprofloxacin (CIP) $5 \mu \mathrm{g}$, nalidixic acid (NA) $30 \mu \mathrm{g}$, chloramphenicol (C) $30 \mu \mathrm{g}$, doxycycline (DO) $30 \mu \mathrm{g}$, cefotaxime (CTX) $30 \mu \mathrm{g}$, trimethoprim-sulfamethoxazole (SXT) 12.5/23.75 $\mu \mathrm{g}$, amoxicillin/nalidixic acid (AMC) 20/10 $\mu \mathrm{g}$, levofloxacin (LEV) $5 \mu \mathrm{g}$, norfloxacin (NOR) $10 \mu \mathrm{g}$, azithromycin (AZM) $15 \mu \mathrm{g}$, danofloxacin (DA) $2 \mu \mathrm{g}$, oxytetracycline (T) $30 \mu \mathrm{g}$, erythromycin (E) $15 \mu \mathrm{g}$, gentamicin (CN) $10 \mu \mathrm{g}$, vancomycin (VA) $30 \mu \mathrm{g}$ and amoxicillin (AX) $30 \mu \mathrm{g}$. The result was interpreted as resistant, intermediate or susceptible based on the inhibitory zone as described by the Clinical and Laboratory Standards Institute (CLSI) [16]. The strains displaying resistance to at least three antibiotic classes were considered multidrug-resistant (MDR) [17]. The L. monocytogenes strain LMEGY1 was used as a quality control organism in antimicrobial susceptibility determination. All samples were tested twice.

\subsection{Molecular Detection of L. monocytogenes from Food Products}

DNA was extracted using QIAamp DNA Mini Kit (Qiagen, Hilden, Germany). The list of primers used in the study is provided in Table 1. Taq PCR Master Mix Kit (Qiagen, Hilden, Germany) was used in the PCR. A $50 \mu \mathrm{L}$ reaction was prepared to contain $25 \mu \mathrm{L}$ PCR Master Mix, $1 \mu \mathrm{L}(10 \mathrm{pmol} / \mu \mathrm{L})$ of each primer, $2 \mu \mathrm{L}(50 \mathrm{ng} / \mu \mathrm{L})$ DNA and the remaining volume needed to reach $50 \mu \mathrm{L}$ was adjusted with deionized water. The following thermal profile was used: initial denaturation at $95^{\circ} \mathrm{C}$ for $3 \mathrm{~min} ; 35$ cycles each consisting of denaturation at $94{ }^{\circ} \mathrm{C}$ for $30 \mathrm{~s}$, annealing at $53{ }^{\circ} \mathrm{C}$ for $15 \mathrm{~s}$ and extension at $72{ }^{\circ} \mathrm{C}$ for $90 \mathrm{~s}$; 
and final extension at $72{ }^{\circ} \mathrm{C}$ for $7 \mathrm{~min}$. PCR products $(15 \mu \mathrm{L})$ were analyzed by agarose gel $(1.5 \%)$ electrophoresis and visualized under UV light in a gel documentation system. The L. monocytogenes LMEGY1 strain was used as a positive control in the PCR.

Table 1. List of PCR primers used in the molecular detection and characterization of L. monocytogenes.

\begin{tabular}{|c|c|c|c|c|}
\hline Targets & Primers & Sequences $\left(5^{\prime}\right.$ to $\left.3^{\prime}\right)$ & Amplicon Size (bp) & Reference \\
\hline \multirow{2}{*}{$16 S$ rRNA } & Forward & CTC CAT AAA GGT GAC CCT & \multirow{2}{*}{938} & \multirow{12}{*}{ [18] } \\
\hline & Reverse & CAG CMG CCG CGG TAA TWC & & \\
\hline \multirow{2}{*}{ hlyA } & Forward & CCT AAG ACG CCA ATC GAA & \multirow{2}{*}{702} & \\
\hline & Reverse & AAG CGCTTG CAA CTG CTC & & \\
\hline \multirow{2}{*}{ inlA } & Forward & AGA TCT AGA CCA AGT TAC AAC GCT TCA & \multirow{2}{*}{255} & \\
\hline & Reverse & TAA TAT CAT TTG CTG TTT TAT CTG TC & & \\
\hline \multirow{2}{*}{ act $A$} & Forward & ACG TGA AGT AAG TCACGT GAT ATT G & \multirow{2}{*}{268} & \\
\hline & Reverse & ACG TGA AGT AAG CTC ACG TGA TAT TG & & \\
\hline \multirow{2}{*}{$\operatorname{prfA}$} & Forward & ACC GCT CAG AAA AGT TCT TC & \multirow{2}{*}{1060} & \\
\hline & Reverse & TCT TGT TCT ATT ATGTCT AGC & & \\
\hline \multirow{2}{*}{ iap } & Forward & ACA AGC TGC ACC TGT TGC AG & \multirow{2}{*}{131} & \\
\hline & Reverse & TGA CAG CGT TGT TAG TAG CA & & \\
\hline
\end{tabular}

\subsection{Sequencing and Phylogenetic Analysis of L. monocytogenes from Food Products}

Three PCR amplicon of the 16S rRNA gene of L. monocytogenes, each from raw milk, fish fillet and minced meat were purified using Gene JET PCR Purification kit (Thermo Scientific, Waltham, MA, USA). The purified PCR products were sequenced from a commercial laboratory (GATC Biotech Company, Konstanz, Germany) in both directions. Nucleotide and amino acid sequence homology analysis among studied isolates and global strains was performed using BLAST 2.0 and PSI-BLAST search programs (http:/ / www.ncbi.nlm.nih.gov/, accessed on 20 March 2021), respectively. Multiple alignments with reference strains as well as the deduction of amino acid sequences were performed using the BioEdit [19], CLUSTALX [20], ClustalW [21], ClustalV [22] and MegAlign software (DNASTAR, Lasergene ${ }^{\circledR}$, Version 7.1.0, Madison, WI, USA) [23]. A neighborjoining phylogenetic tree was built using MegAlign software. A random bootstrapping value of 111 was applied [21]. The partial nucleotide sequences of the three L. monocytogenes strains from the fish fillet, minced meat and raw milk were submitted in the GenBank with accession number MW090062, MW090063 and MW090064, respectively.

\subsection{Statistical Analysis}

To show the multidrug resistance profile of L. monocytogenes isolates, an UpSetR plot was prepared using an online platform (https://gehlenborglab.shinyapps.io/upsetr/, accessed on 21 April 2021).

\section{Results}

\subsection{Prevalence of Listeria Species and L. monocytogenes in Different Food Products}

The overall prevalence of L. monocytogenes was $6.8 \%(n=17)$, while other Listeria species were as followed: L. innoca $3.2 \%(n=8)$, L. grayi $2.4 \%(n=6)$, L. ivanovii $0.4 \%(n=1)$ and $L$. welshimeri $0.8 \%(n=2)$. Among the different food samples, L. monocytogenes was most commonly detected in minced meat (14\%) followed by fish fillet $(8 \%)$, sausage $(6 \%)$ and milk (6\%) (Table 2). Analysis of the ice cream samples yielded no L. monocytogenes. 
Table 2. Prevalence of Listeria monocytogenes in food products.

\begin{tabular}{cccccccccc}
\hline \multicolumn{2}{c}{$\begin{array}{c}\text { Raw Milk } \\
(\boldsymbol{n}=\mathbf{5 0 )}\end{array}$} & \multicolumn{2}{c}{$\begin{array}{c}\text { Ice Cream } \\
(\boldsymbol{n}=\mathbf{5 0 )}\end{array}$} & \multicolumn{2}{c}{$\begin{array}{c}\text { Minced Meat } \\
(\boldsymbol{n}=\mathbf{5 0 )}\end{array}$} & \multicolumn{2}{c}{$\begin{array}{c}\text { Fish Fillet } \\
(\boldsymbol{n}=\mathbf{5 0 )}\end{array}$} & \multicolumn{2}{c}{$\begin{array}{c}\text { Sausage } \\
(\boldsymbol{n}=\mathbf{5 0})\end{array}$} \\
\hline No. & $\%$ & No. & $\%$ & No. & $\%$ & No. & $\%$ & No. & $\%$ \\
\hline 3 & 6 & 0 & 0 & 7 & 14 & 4 & 8 & 3 & 6 \\
\hline
\end{tabular}

$\%$ was estimated according to the total number of each sample (50).

Typical colony characters of L. monocytogenes on Oxford medium appeared as gray to black color colonies bounded by a black halo. A green to bluish colony was observed in CHROM agar medium. On the $5 \%$ sheep blood agar medium, L. monocytogenes showed a clear narrow $\beta$-hemolysis. A series of biochemical tests were conducted to confirm and differentiate L. monocytogenes and other Listeria species (Supplementary Table S1). L. monocytogenes appeared as Gram positive coccobacilli, catalase and CAMP test positive as well as fermented rhamnose with acid production, while negative for fermentation of mannitol and xylose (Supplementary Table S1).

\subsection{Antibiogram of L. monocytogenes Isolates from Food Products}

Antimicrobial resistance profiles of L. monocytogenes isolates were tested against seventeen antibiotics belonging to eight different antibiotic classes using the disc diffusion method (Table 3). L. monocytogenes isolates showed high susceptibility to $\beta$-lactams (amoxicillinclavulanic acid, cefotaxime and amoxicillin), norfloxacin, erythromycin, gentamicin and vancomycin. While, high resistance was observed against tetracycline (oxytetracycline and doxycycline), trimethoprim-sulfamethoxazole and chloramphenicol (Table 3). An overall similar antimicrobial resistance profile was observed in L. monocytogenes isolates from different sources such as milk, fish fillet, sausage and minced meat (Supplementary Table S2).

Table 3. Antimicrobial resistance profiles of L. monocytogenes isolates from food products.

\begin{tabular}{|c|c|c|c|c|c|c|c|}
\hline \multirow[t]{2}{*}{ Antibiotics } & \multirow[t]{2}{*}{ Antimicrobial Classes } & \multicolumn{2}{|c|}{ Resistant } & \multicolumn{2}{|c|}{ Intermediate } & \multicolumn{2}{|c|}{ Sensitive } \\
\hline & & No & $\%$ & No & $\%$ & No & $\%$ \\
\hline Amoxicillin-Clavulanic acid (AMC) 20/10 $\mu \mathrm{g}$ & $\beta$-lactams & 3 & 17.7 & 1 & 5.9 & 13 & 76.4 \\
\hline Cefotaxime (CTX) $30 \mu \mathrm{g}$ & $\beta$-lactams & 3 & 17.7 & 2 & 11.8 & 12 & 70.5 \\
\hline Amoxicillin (AX) $30 \mu \mathrm{g}$ & $\beta$-lactams & 5 & 29.5 & 1 & 5.9 & 11 & 64.6 \\
\hline Norfloxacin (NOR) $10 \mu \mathrm{g}$ & Fluoroquinolones & 2 & 11.8 & 1 & 5.9 & 14 & 82.3 \\
\hline Ciprofloxacin (CIP) $5 \mu \mathrm{g}$ & Fluoroquinolones & 5 & 29.4 & 2 & 11.8 & 10 & 58.8 \\
\hline Levofloxacin (LEV) $5 \mu \mathrm{g}$ & Fluoroquinolones & 7 & 41.2 & 2 & 11.8 & 8 & 47 \\
\hline Danofloxacin (DA) $2 \mu \mathrm{g}$ & Fluoroquinolones & 7 & 41.2 & 2 & 11.8 & 8 & 47 \\
\hline Nalidixic acid (NA) $30 \mu \mathrm{g}$ & Fluoroquinolones & 3 & 17.7 & 10 & 58.8 & 4 & 23.5 \\
\hline Amikacin (AK) $30 \mu \mathrm{g}$ & Aminoglycosides & 5 & 29.4 & 1 & 5.9 & 11 & 64.6 \\
\hline Gentamicin $(\mathrm{CN}) 10 \mu \mathrm{g}$ & Aminoglycosides & 5 & 29.5 & 2 & 11.8 & 10 & 58.7 \\
\hline Erythromycin (E) $15 \mu \mathrm{g}$ & Macrolides & 5 & 29.5 & 1 & 5.9 & 11 & 64.6 \\
\hline Azithromycin (AZM) $15 \mu \mathrm{g}$ & Macrolides & 7 & 41.2 & 7 & 41.2 & 3 & 17.7 \\
\hline Doxycycline (DO) $30 \mu \mathrm{g}$ & Tetracycline & 11 & 64.6 & 3 & 17.7 & 3 & 17.7 \\
\hline Oxytetracycline $(\mathrm{T}) 30 \mu \mathrm{g}$ & Tetracycline & 13 & 76.4 & 1 & 5.9 & 3 & 17.7 \\
\hline Chloramphenicol (C) $30 \mu \mathrm{g}$ & Chloramphenicol & 12 & 70.5 & 2 & 11.8 & 3 & 17.7 \\
\hline Trimethoprim-Sulfamethoxazole (SXT) 12.5/23.75 $\mu \mathrm{g}$ & Sulfonamides & 13 & 76.4 & 2 & 11.8 & 2 & 11.8 \\
\hline Vancomycin (VA) $30 \mu \mathrm{g}$ & Glycopeptides & 5 & 29.5 & 2 & 11.8 & 10 & 58.7 \\
\hline
\end{tabular}

\footnotetext{
$\%$ was estimated according to the total number of L. monocytogenes isolates $(n=17)$.
} 
Next, multidrug resistance profiles of the 17 L. monocytogenes isolates were tested. All L. monocytogenes isolates were multidrug-resistant against 3 to 11 different antibiotics belonging to 3 to 7 antibiotic classes in 17 different combinations (Figure 1).

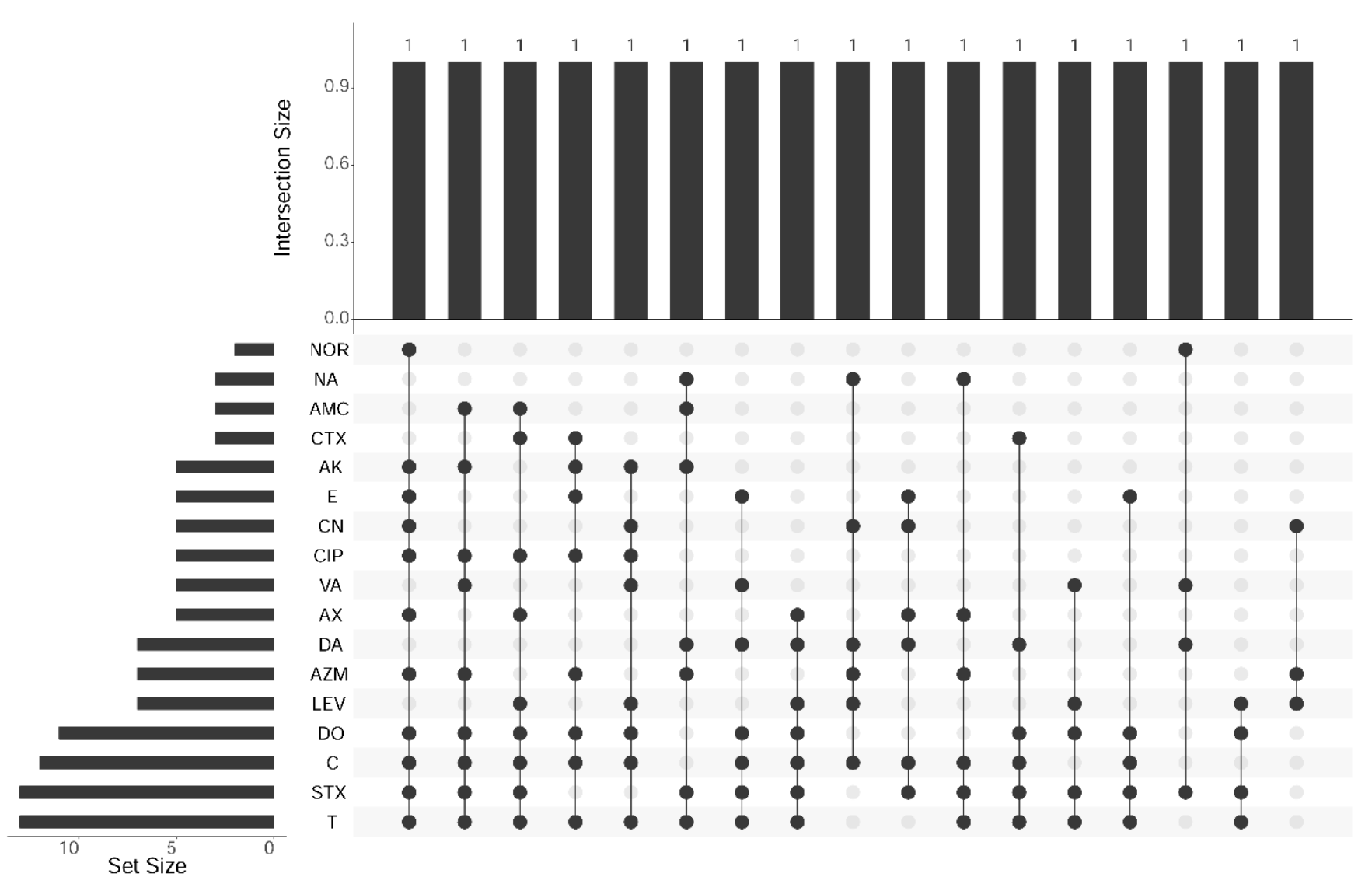

Figure 1. The multidrug-resistant profiling of L. monocytogenes isolates from food products. Note: amikacin (AK), ciprofloxacin (CIP), nalidixic acid (NA), chloramphenicol (C), doxycycline (DO), cefotaxime (CTX), trimethoprimsulfamethoxazole (SXT), amoxicillin/nalidixic acid (AMC), levofloxacin (LEV), norfloxacin (NOR), azithromycin (AZM), danofloxacin (DA), oxytetracycline $(\mathrm{T})$, erythromycin $(\mathrm{E})$, gentamicin $(\mathrm{CN})$, vancomycin $(\mathrm{VA})$ and amoxicillin $(\mathrm{AX})$.

\subsection{Screening of Different Virulence Genes in L. monocytogenes from Food Products}

Next, we applied multiplex PCR for molecular detection of the L. monocytogenes and screening five virulence-associated genes of the bacteria. Amplification of $938 \mathrm{bp}$ fragment of the $16 \mathrm{~S} r \mathrm{RNA}$ gene was found in all of the 17 tested isolates, confirming the L. monocytogenes species (Figure 2). While, the screening of five virulence-associated genes in L. monocytogenes revealed the hlyA $(n=12,70.6 \%)$ and iap $(n=12,70.6 \%)$ as the most prevalent genes followed by the act $A$ gene $(n=9,52.9 \%)$ (Figures 2 and 3). However, inlA and $\operatorname{prf} A$ genes were absent in all of the tested isolates. Of note, the simultaneous presence of three virulence genes ( $h l y A$, iap and act $A$ ) in six isolates, two of the three virulence genes ( hlyA, iap or actA) in six isolates was also detected. Taken together, L. monocytogenes isolates from food products carried multiple virulence genes, indicating their pathogenic potential. 


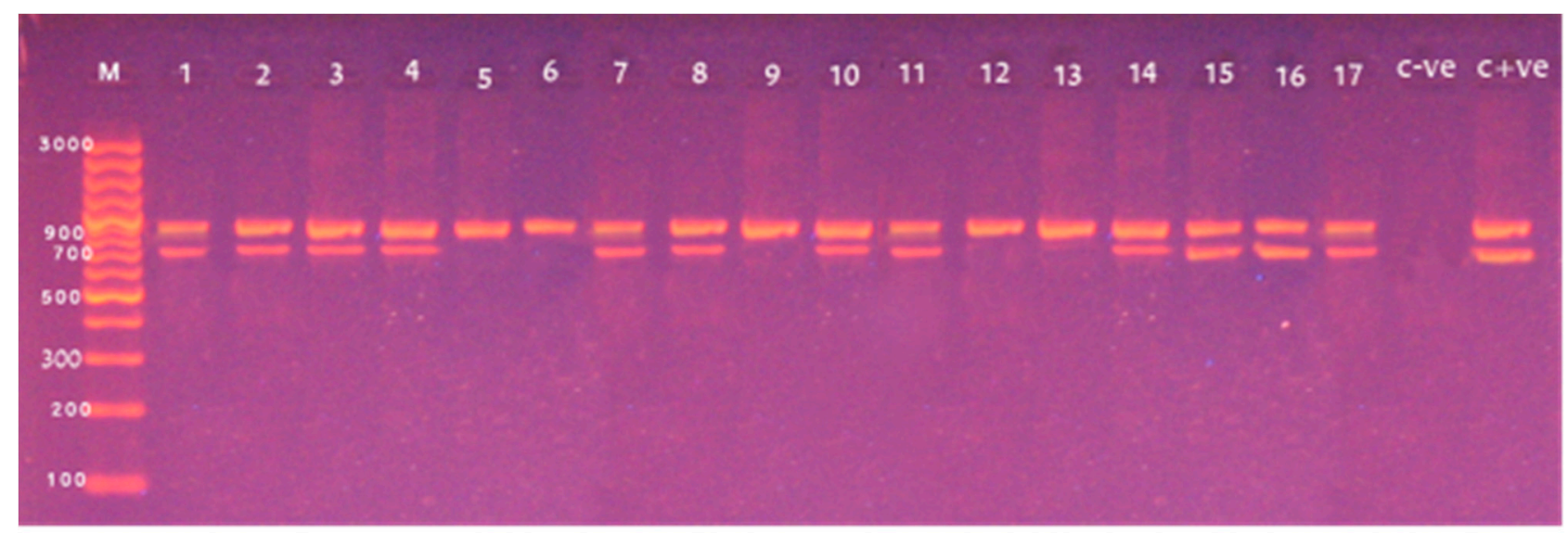

Figure 2. Amplification of $16 S$ rRNA and hlyA genes of L. monocytogenes at $938 \mathrm{bp}$ and $702 \mathrm{bp}$, respectively, by multiplex PCR. Lane M: 100 bp DNA ladder; Lane 1-17 positive samples for 16S rRNA; Lane 1-3 (raw milk), 4, 7-8 (fish fillet), 10-11 (sausage) and 14-17 (minced meat) were positive for the hlyA gene; Lane C -ve: Control Negative; Lane C +ve: Control Positive.

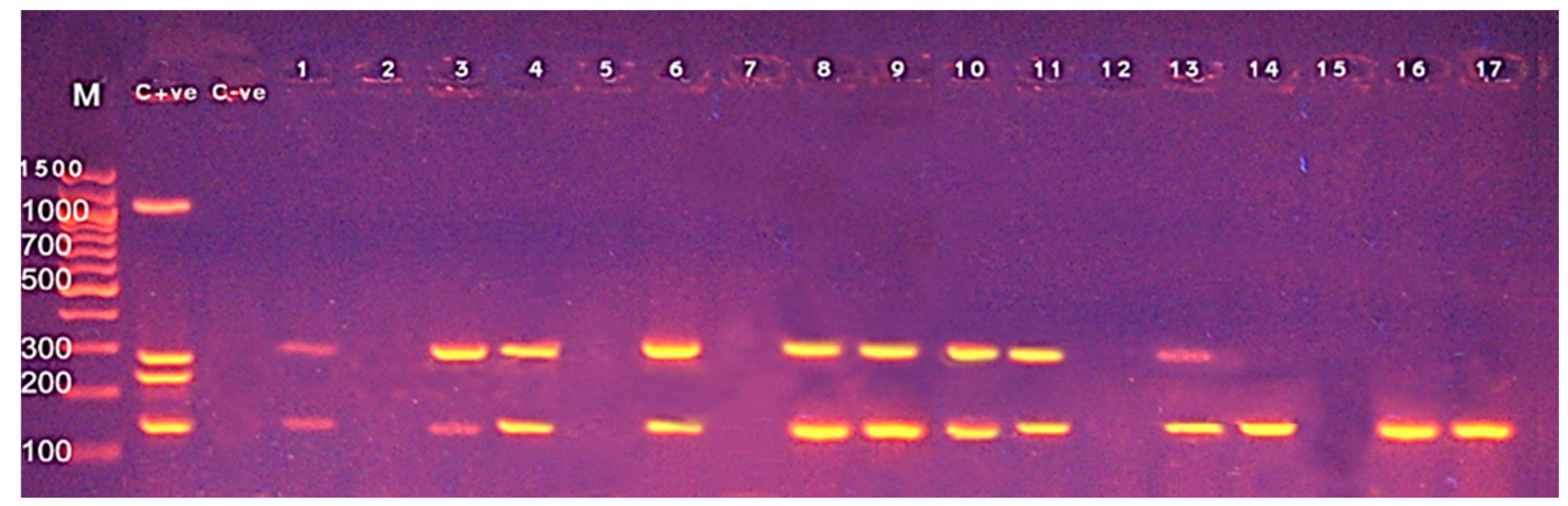

Figure 3. Amplification of inlA, actA, prfA and iap genes of L. monocytogenes at $255 \mathrm{bp}, 268 \mathrm{bp}, 1060 \mathrm{bp}$ and $131 \mathrm{bp}$, respectively, by multiplex PCR. Lane M: 100 bp DNA ladder; Lane C +ve: Control Positive; Lane C -ve: Control Negative; Lane 1, 3, 4, 6 (minced meat), 8-11 (fish fillet), 13-14 (raw milk), 16-17 (sausage) were positive for the iap gene at $131 \mathrm{bp}$. While lane 1, 3, 4 (minced meat), 6, 8 (raw milk), 9, 10 (fish fillet) and 11, 13 (sausage) were positive for the act $A$ gene at $268 \mathrm{bp}$. The $\mathrm{prf} A$ and $\mathrm{inl} A$ genes were not detected in any samples.

\subsection{Sequence Analysis of L. monocytogenes Isolates from Food Products}

The $16 S$ rRNA sequence analysis was used for evaluating the genetic similarity of L. monocytogenes isolates from fish fillet, minced meat and raw milk samples with global strains. The partial sequence data were submitted to the GenBank with accession number MW090062, MW090063 and MW090064. The study isolates showed a very high nucleotide similarity (99.1-99.8\%) with L. monocytogenes strains isolated in Turkey and Germany from minced meat and food origin with accession number MT633107.1 (strain: ka89-2), and CP054846 (strain: BfR-LI-00752), respectively (Figure 4). Additionally, the near identity was also noticed with L. monocytogenes strain identified from the Massachusetts listeriosis outbreak in the USA (accession number CP023862, strain: ScottA). As well as one strain from rabbit tissue from United Kingdom (accession number CP023861, strain: EGD-e) had identical nucleotides similarity (99.6-100\%) with our strains from food samples. 


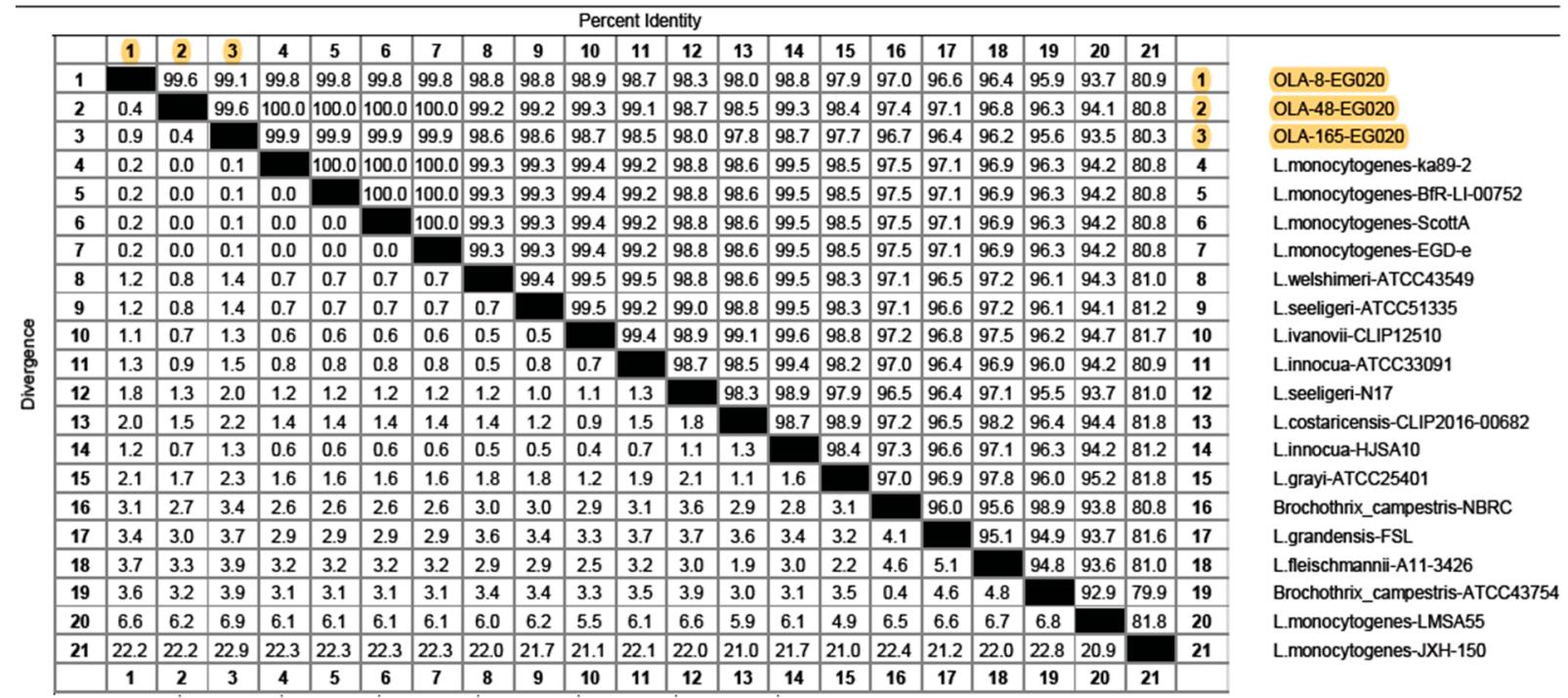

Figure 4. Nucleotide percent identity and divergence between the L. monocytogenes from raw milk, fish fillet and minced meat and related strains retrieved from GenBank. Sequences (highlighted in yellow color) from raw milk (OLA-165-EG020, accession number MW090064), fish fillet (OLA-8-EG020, accession number MW090062) and minced meat (OLA-48-EG020, accession number MW090063) were generated in this study.

The phylogenetic tree clustered our three L. monocytogenes strains with other Listeria species including L. welshimeri (strain ATCC 43549), L. seeligeri (strain ATCC 51335) and L. innocua (ATCC 33091) strains from China with accession number JF967629.1, JF967627.1 and JF967626.1, respectively (Figure 5). Furthermore, several Listeria strains shared sequence homology with the study isolates including one isolate from braised chickens in China (MT781377.1, strain HJSA10), four strains from different countries and localities including L. ivanovii from the USA (NR_036808.1, strain CLIP 12510), L. seeligeri from Turkey (MK490993.1, strain N17), L. costaricensis from France (MK174378.1, strain CLIP 2016/00682) and L. grayi from Switzerland (JN852815.1, strain ATCC 25401). On the other hand, a distinct diversity was detected in the phylogenic tree with two L. monocytogenes isolates from salads in Nigeria (KY053294.1, strain LMSA55) and deep-sea sediment in the Pacific Ocean (KR012147.1, strain JXH-150) (Figures 4 and 5).

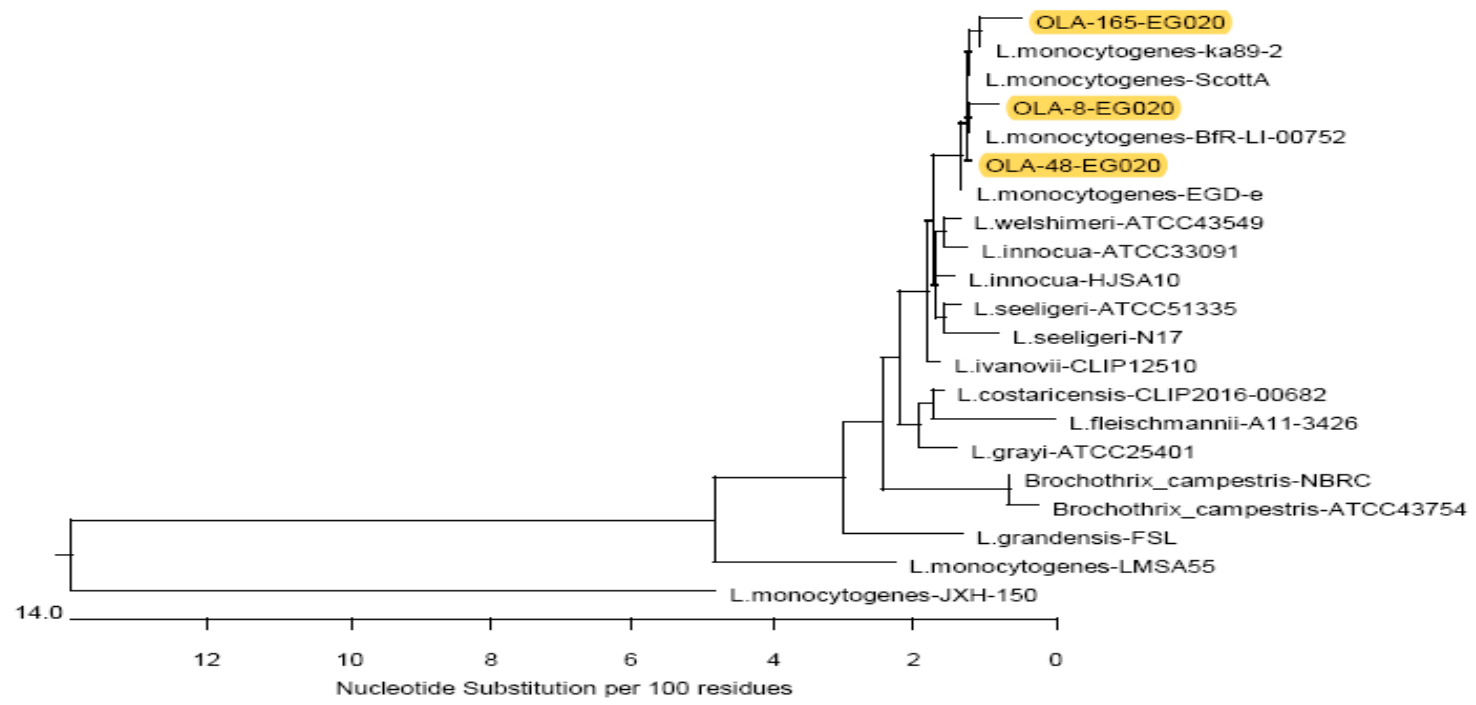

Figure 5. Neighbor-joining phylogenetic tree of Listeria monocytogenes from raw milk, fish fillet and minced meat based on the partial $16 S$ rRNA gene sequences. Sequences (highlighted in yellow color) from raw milk (OLA-165-EG020, accession number MW090064), fish fillet (OLA-8-EG020, accession number MW090062) and minced meat (OLA-48-EG020, accession number MW090063) were generated in this study. 


\section{Discussion}

Listeria monocytogenes possesses a significant public health significance due to frequent contamination of food products [24]. In Egypt, L. monocytogenes enters into human food chain primarily through contaminated meat and chicken products [9]. In particular, the ability of L. monocytogenes to grow in the refrigerator or cooled condition in varieties of food products makes the pathogen difficult to control [3]. Detection of the bacteria in food products at retail outlets indicates a major defect in the quality control measures [25].

Here, the overall prevalence rate of $L$. monocytogenes from 250 different food products was $6.8 \%$, while other Listeria species, L. innoca, L. grayi, L. ivanovii and L. welshimeri were detected in $3.2 \%, 2.4 \%, 0.4 \%$ and $0.8 \%$ of the samples, respectively. More specifically, the L. monocytogenes was found in $14 \%, 8 \%, 6 \%$ and $6 \%$ of minced meat, fish fillet, sausage and raw milk samples, respectively, while none of the ice cream samples showed positive growth of the bacteria. Our study corroborates a recent study that demonstrated $6 \%$ and $4 \%$ prevalences of L. monocytogenes in urban and rural areas of Egypt, respectively [25]. The study also detected a high prevalence of $L$. monocytogenes in minced meat $(56 \%)$, poultry meat (18\%), tilapia fish (6\%) and raw milk (10\%) in Egypt [25]. A similar study in the Czech Republic during 2004-2008 reported L. monocytogenes in $5.2 \%, 3.4 \%$ and $1.8 \%$ of the delicatessen, meat and dairy products, respectively [26]. In contrast, Oliveira and colleagues isolated L. monocytogenes in $17.9 \%$ of meat cuts and $8.3 \%$ from cuts after packing meat samples [27]. In Ethiopia, the prevalence of Listeria species and L. monocytogenes in ready-to-eat foods was found $25 \%$ and $6.25 \%$, respectively [12]. A similar study in Portugal detected a $7 \%$ prevalence of L. monocytogenes in 1035 food products (milk, meat, fish, flour) indicating a potential risk for consumers [28]. The variation in the detection rate of $L$. monocytogenes among different studies in varieties of food products could be explained by types of foods, sample size, geographic area and the degree of sanitary measures applied during food processing and manufacture.

The antibiogram profile of the 17 L. monocytogenes isolates against seventeen antibiotics displayed a high sensitivity to norfloxacin (82.3\%), amoxicillin-clavulanic acid (76.4\%), cefotaxime (70.5\%), erythromycin (64.6\%), amoxicillin (64.6\%), gentamicin $(58.7 \%)$ and vancomycin $(58.7 \%)$. While, high resistance was perceived against oxytetracycline $(76.4 \%)$ and trimethoprim-sulfamethoxazole $(76.4 \%)$, chloramphenicol (70.5\%), doxycycline $(64.6 \%)$, levofloxacin $(41.2 \%)$ and azithromycin $(41.2 \%)$. The antimicrobial profiles of $L$. monocytogenes strains recovered from four different sources such as raw milk, fish fillet, sausage and minced meat were broadly similar. Moreover, all of the 17 L. monocytogenes isolates were multidrug-resistant. Our findings corroborate an earlier study [29] which showed high resistance of L. monocytogenes isolates against penicillin, amoxicillin/clavulanic acid, tetracycline and chloramphenicol. Moreover, L. monocytogenes isolated from fish and fish products in India showed resistance to multiple antibiotics [30]. High susceptibility of L. monocytogenes to several antibiotics including amoxicillin, cephalothin, cloxacillin and sulfamethoxazole and high resistance rate against penicillin, nalidixic acid, tetracycline and chloramphenicol were also found in isolates from several ready-to-eat food products of milk, meat and fish origin [12]. Another study also reported antimicrobial resistance to two or more antibiotics of $36 \mathrm{~L}$. monocytogenes from raw milk which indicates a public health threat to the consumers [31]. On the contrary, a recent study showed $100 \%$ susceptibility of the L. monocytogenes isolates to most of the tested antibiotics which emphasized the need for the continuous monitoring of antimicrobial susceptibility pattern and their effects on public health [27]. Another study found that resistance to penicillin and erythromycin were common in $44.4 \%$ and $60 \%$ of the L. monocytogenes isolated from milk and clinical specimens, respectively [2].

The PCR offers rapid and sensitive detection of L. monocytogenes in food products which is crucial in the food industry [32]. We employed a multiplex PCR technique to detect $L$. monocytogenes by amplifying the $16 S r R N A$ gene and screened five virulence genes of L. monocytogenes. Amplification of the $16 S$ rRNA genes was found in all of the tested isolates. Screening of the five virulence genes showed that the $h l y A$, iap and $a c t A$ were 
the most detected virulence genes with the prevalence rate of $70.6 \%, 70.6 \%$ and $52.9 \%$, respectively. Of note, simultaneous detection of the three virulence genes (hlyA, iap and act $A$ ) was found in six L. monocytogenes isolates. Our findings support a recent study in Egypt that detected four virulence genes (inlA, actA, prfA and hlyA) in L. monocytogenes isolates from animal food products [25]. Harb and colleagues showed that the MPCR targeting the $16 S r R N A$ and $h l y A$ genes can effectively detect L. monocytogenes in food samples [33]. In a comparative study in Nigeria, Usman and colleagues used the mPCR to detect multiple virulence-related genes ( $\operatorname{rrf} A$, inlA, hly $A$, act $A$ and iap) in L. monocytogenes from milk and milk products where $25 \%$ of them carried one or two of the virulence genes [18]. In Egypt, Abdellrazeq and colleagues examined five virulence genes (prfA, hly $A$, act $A$, inlA and prs) in L. monocytogenes from various fish types by $\mathrm{MPCR}$ and detected prs gene in all tested isolates while only seven isolates carried other virulence genes [34]. In India, Kaur and colleagues tested 335 food samples (chicken, pork and fish) from various retail outlets and found that all L. monocytogenes isolates possess the prfA, plcA, $a c t A, h l y A$ and iap virulence-related genes [35]. Furthermore, Haj Hosseini and colleagues demonstrated the prfA gene in all L. monocytogenes from contaminated foods in Iran [8]. Several virulent genes were also detected in $L$. monocytogenes from fish and fish products in India [30]. Of note, the two virulence-related genes, $\operatorname{prf} A$ and $i n l A$ were not found in any of the tested isolates. Our observations might be attributed to complete absence or presence of sequence variations in sites targeted by applied primers within genes found in L. monocytogenes isolates of our study. Since we detected no hemolytic activity differences on sheep blood agar between our all isolates and the reference strain used L. monocytogenes strain LMEGY1 with an intact prfA gene, the lack of prfA gene among our strains can however be ruled out.

The partial sequencing of the $16 S r R N A$ gene was performed to assess the genetic homology among L. monocytogenes isolates from milk, fish fillet and minced meat as well as among related global sequences. Our findings showed a high nucleotide similarity (99.1-99.8\%) between L. monocytogenes strains from various global clones. The phylogenetic tree clustered the three L. monocytogenes isolates from this study with other Listeria species including L. welshimeri, L. seeligeri and L. innocua strains. In addition, an apparent diversity was found in the phylogenetic tree with some other strains. These findings corroborate with other studies $[36,37]$ which recorded a close association (more than $99 \%$ nucleotide similarity) between the members of Listeria species and this highlighted the significance of the 16S rRNA gene in differentiating Listeria species. Nucleotide sequencing and multilocus sequence typing (MLST) techniques are suggested to be more precise techniques for recognizing the clonal complexes (CC) of L. monocytogenes strains and phylogenetic characters among different Listeria strains in a population [38]. The sequencing analysis of the 16S rRNA gene of L. monocytogenes recovered from bulk tank milk in the USA described a high genetic diversity with many strains encoding virulence markers that were linked with serious human infections [4]. The comparison with global clones grouped the L. monocytogenes isolates into two distinct clusters, linage A, which are typically associated with epidemic listeriosis, and lineage $B$, which are mostly associated with sporadic cases of listeriosis [18]. Thus, our study emphasizes that these local isolates may have a potentials public health concern for humans through the food chain.

\section{Conclusions}

The study demonstrates the impact of L. monocytogenes as a major contaminant of various food products and the need for more attention about the awareness and hygienic measures in the food industry. Most of the L. monocytogenes from food products were multidrug-resistant, adding further burden to the existing global antimicrobial resistance problems. The sequencing analysis reported a high nucleotide sequence similarity of the study isolates with many global clones, indicating the widespread circulation of such strains between different countries via the food trading industry. Therefore, evidence-based 
recommendations and continuous education for workers particularly in the food industry are necessary to prevent food contamination and the emergence of resistant strains.

Supplementary Materials: The following are available online at https:/ / www.mdpi.com/article/ 10.3390/foods10061381/s1, Table S1: Biochemical identification of Listeria monocytogenes and other Listeria species, Table S2: Antimicrobial resistance profiles of Listeria monocytogenes isolates from food products.

Author Contributions: Conceptualization, E.E.A., W.S.M. and G.A.F.-E.; methodology, E.E.A., W.S.M., O.H.H., G.A.F.-E. and M.N.; software, M.N., A.G. and A.A.; validation, E.E.A., G.A.F.-E. and W.F.A.; formal analysis, M.N., A.G. and A.A.; investigation, E.E.A., W.S.M., O.H.H. and G.A.F.-E.; resources, M.N. and W.F.A.; data curation, E.E.A. and M.N.; writing-original draft preparation, E.E.A., W.S.M., A.G, W.F.A. and A.A.; writing-review and editing, W.S.M., M.N., A.G. and A.A.; visualization, E.E.A., M.N. and G.A.F.-E.; supervision, E.E.A. and W.S.M.; project administration, E.E.A.; funding acquisition, A.G. All authors have read and agreed to the published version of the manuscript.

Funding: This research was partially funded through Taif University Researchers Supporting Project number (TURSP-2020/39), Taif University, Taif, Saudi Arabia.

Institutional Review Board Statement: This study was performed according to the rules and regulations of the Egyptian Ministry of Health and Faculty of Veterinary of Medicine, the University of Sadat City, Egypt (Approval no. VUSC013220).

Informed Consent Statement: Not applicable.

Data Availability Statement: All authors agree that the data presented in this study are openly available through MDPI publisher platform or others without any restriction.

Acknowledgments: The authors gratefully thank the Center of Excellence for Screening of Environmental Contaminants (CESEC, STDF 31290), Benha University Egypt. The appreciation extends to Taif University Researchers Supporting Project number (TURSP-2020/39), Taif University, Taif, Saudi Arabia. The authors are grateful to Mohammad Rafiqul Islam of Department of Pathology, Bangladesh Agricultural University for his support in language editing and proofreading the manuscript.

Conflicts of Interest: The authors declare no conflict of interest. The funders had no role in the design of the study; in the collection, analyses or interpretation of data; in the writing of the manuscript, or in the decision to publish the results.

\section{References}

1. Osman, K.M.; Kappell, A.D.; Fox, E.M.; Orabi, A.; Samir, A. Prevalence, pathogenicity, virulence, antibiotic resistance, and phylogenetic analysis of biofilm producing Listeria monocytogenes isolated from different ecological niches in Egypt: Food, humans, animals, and environment. Pathogens 2020, 9, 5. [CrossRef]

2. Skowron, K.; Wałecka-Zacharksa, E.; Grudlewska, K.; Wiktorczyk, N.; Kaczmarek, A.; Gryń, G.; Kwiecińska-Piróg, J.; Juszczuk, K.; Paluszak, Z.; Kosek-Paszkowska, K.; et al. Characteristics of Listeria monocytogenes strains isolated from milk and humans and the possibility of milk-borne strains transmission. Polish J. Microbiol. 2019, 68, 353-369. [CrossRef] [PubMed]

3. Vinothkumar, R.; Arunagiri, K.; Sivakumar, T. Studies on pathogenic Listeria monocytogenes from marine food resources. Int. J. Curr. Microbiol. Appl. Sci. 2013, 2, 86-93.

4. Kim, S.W.; Haendiges, J.; Keller, E.N.; Myers, R.; Kim, A.; Lombard, J.E.; Karns, J.S.; Van Kessel, J.A.S.; Haley, B.J. Genetic diversity and virulence profiles of Listeria monocytogenes recovered from bulk tank milk, milk filters, and milking equipment from dairies in the United States (2002 to 2014). PLoS ONE 2018, 13, e0197053. [CrossRef] [PubMed]

5. Maury, M.M.; Bracq-Dieye, H.; Huang, L.; Vales, G.; Lavina, M.; Thouvenot, P.; Disson, O.; Leclercq, A.; Brisse, S.; Lecuit, M. Hypervirulent Listeria monocytogenes clones' adaption to mammalian gut accounts for their association with dairy products. Nat. Commun. 2019, 10, 2488. [CrossRef]

6. Camejo, A.; Carvalho, F.; Reis, O.; Leitão, E.; Sousa, S.; Cabanes, D. The arsenal of virulence factors deployed by Listeria monocytogenes to promote its cell infection cycle. Virulence 2011, 2, 379-394. [CrossRef]

7. Ward, T.J.; Gorski, L.; Borucki, M.K.; Mandrell, R.E.; Hutchins, J.; Pupedis, K. Intraspecific phylogeny and lineage group identification based on the prfA virulence gene cluster of Listeria monocytogenes. J. Bacteriol. 2004, 186, 4994-5002. [CrossRef] [PubMed]

8. Haj Hosseini, A.; Sharifan, A.; Tabatabaee, A. Isolation of Listeria monocytogenes from meat and dairy products. J. Med. Microbiol. Infect. Dis. 2014, 2, 159-162. 
9. $\quad$ El-Malek, A.M.A.; Ali, S.F.H.; Hassanein, R.; Mohamed, M.A.; Elsayh, K.I. Occurrence of Listeria species in meat, chicken products and human stools in Assiut city, Egypt with PCR use for rapid identification of Listeria monocytogenes. Vet. World 2010, 3, 353-359. [CrossRef]

10. Bloom, G.; Merrett, G.B.; Wilkinson, A.; Lin, V.; Paulin, S. Antimicrobial resistance and universal health coverage. BMJ Glob. Health 2017, 2, 1-6. [CrossRef]

11. Friedman, N.D.; Temkin, E.; Carmeli, Y. The negative impact of antibiotic resistance. Clin. Microbiol. Infect. 2016, 22, 416-422. [CrossRef]

12. Garedew, L.; Taddese, A.; Biru, T.; Nigatu, S.; Kebede, E.; Ejo, M.; Fikru, A.; Birhanu, T. Prevalence and antimicrobial susceptibility profile of Listeria species from ready-to-eat foods of animal origin in Gondar Town, Ethiopia. BMC Microbiol. 2015, 15, 100. [CrossRef]

13. Monufia Governorate-Wikipedia. Available online: https://en.wikipedia.org/wiki/Monufia_Governorate (accessed on 21 March 2021).

14. Scotter, S.L.; Langton, S.; Lombard, B.; Schulten, S.; Nagelkerke, N.; In't Veld, P.H.; Rollier, P.; Lahellec, C. Validation of ISO method 11290. Part 1-Detection of Listeria monocytogenes in foods. Int. J. Food Microbiol. 2001, 64, 295-306. [CrossRef]

15. Wilkinson, H.W. CAMP-disk test for presumptive identification of group B streptococci. J. Clin. Microbiol. 1977, 6, 42-45. [CrossRef]

16. CLSI. Performance Standards for Antimicrobial Susceptibility Testing; CLSI: Tucson, AZ, USA, 2017; ISBN 978-1-56238-804-1.

17. Magiorakos, A.P.; Srinivasan, A.; Carey, R.B.; Carmeli, Y.; Falagas, M.E.; Giske, C.G.; Harbarth, S.; Hindler, J.F.; Kahlmeter, G.; Olsson-Liljequist, B.; et al. Multidrug-resistant, extensively drug-resistant and pandrug-resistant bacteria: An international expert proposal for interim standard definitions for acquired resistance. Clin. Microbiol. Infect. 2012, 18, 268-281. [CrossRef]

18. Usman, U.B.; Kwaga, J.K.P.; Kabir, J.; Olonitola, O.S.; Radu, S.; Bande, F. Molecular Characterization and Phylogenetic Analysis of Listeria monocytogenes isolated from milk and milk products in Kaduna, Nigeria. Can. J. Infect. Dis. Med. Microbiol. $2016,2016$. [CrossRef]

19. Hall, T.; Biosciences, I.; Carlsbad, C. BioEdit: An important software for molecular biology. GERF Bull. Biosci. $2011,2,60-61$.

20. Ball, N.L.; Adams, C.R.; Xia, W. Overcoming the elusive problem of IS/IT alignment: Conceptual and methodological considerations. In Proceedings of the Ninth Americas Conference on Information Systems, Tampa, FL, USA, 4-6 August 2003; pp. 1669-1676.

21. Thompson, J.D.; Higgins, D.G.; Gibson, T.J. CLUSTAL W: Improving the sensitivity of progressive multiple sequence alignment through sequence weighting, position-specific gap penalties and weight matrix choice. Nucleic Acids Res. 1994, 22, 4673-4680 [CrossRef]

22. Higgins, D.G.; Sharp, P.M. Fast and sensitive multiple sequence alignments on a microcomputer. Bioinformatics 1989, 5, 151-153. [CrossRef]

23. Kumar, S.; Tamura, K.; Nei, M. MEGA3: Integrated software for molecular evolutionary genetics analysis and sequence alignment. Brief. Bioinform. 2004, 5, 150-163. [CrossRef]

24. Taha Said Ahmed, S.S.; Ahmed Tayeb, B. Isolation and molecular detection of Listeria monocytogenes in minced meat, frozen chicken and cheese in Duhok Province, Kurdistan region of Iraq. J. Food Microbiol. Saf. Hyg. 2017, 2, 10-13. [CrossRef]

25. El-Demerdash, A.S.; Raslan, M.T. Molecular characterization of Listeria monocytogenes isolated from different animal-origin food items from urban and rural areas. Adv. Anim. Vet. Sci. 2019, 7, 51-56. [CrossRef]

26. Gelbíčová, T.; Karpíšková, R. Occurrence and characteristics of Listeria monocytogenes in ready-to-eat food from retail market in the Czech Republic. Czech. J. Food Sci. 2009, 27, 3-7. [CrossRef]

27. Oliveira, T.S.; Varjão, L.M.; da Silva, L.N.N.; de Castro Lisboa Pereira, R.; Hofer, E.; Vallim, D.C.; de Castro Almeida, R.C. Listeria monocytogenes at chicken slaughter house: Occurrence, genetic relationship among isolates and evaluation of antimicrobial susceptibility. Food Control. 2018, 88, 131-138. [CrossRef]

28. Mena, C.; Almeida, G.; Carneiro, L.; Teixeira, P.; Hogg, T.; Gibbs, P.A. Incidence of Listeria monocytogenes in different food products commercialized in Portugal. Food Microbiol. 2004, 21, 213-216. [CrossRef]

29. Akrami-Mohajeri, F.; Derakhshan, Z.; Ferrante, M.; Hamidiyan, N.; Soleymani, M.; Conti, G.O.; Tafti, R.D. The prevalence and antimicrobial resistance of Listeria spp in raw milk and traditional dairy products delivered in Yazd, Central Iran (2016). Food Chem. Toxicol. 2018, 114, 141-144. [CrossRef]

30. Basha, K.A.; Kumar, N.R.; Das, V.; Reshmi, K.; Rao, B.M.; Lalitha, K.V.; Joseph, T.C. Prevalence, molecular characterization, genetic heterogeneity and antimicrobial resistance of Listeria monocytogenes associated with fish and fishery environment in Kerala, India. Lett. Appl. Microbiol. 2019, 69, 286-293. [CrossRef]

31. Girma, Y. Isolation, Identification and antimicrobial susceptibility of Listeria species from raw bovine milk in Debre-Birhan Town, Ethiopia. Ethiop. J. Zoonotic Dis. Public Health 2018, 2, 4.

32. Somer, L.; Kashi, Y. A PCR method based on 16S rRNA sequence for simultaneous detection of the genus Listeria and the species Listeria monocytogenes in food products. J. Food Prot. 2003, 66, 1658-1665. [CrossRef]

33. Harb, O.; Elbab, G.; Shawish, R.; Mousa, W.; Abdeen, E. Genetic detection of Listeria monocytogenes recovered from fillet fish samples. Alexandria J. Vet. Sci. 2020, 67, 74. [CrossRef]

34. Abdellrazeq, G.; Kamar, A.; ElHoushy, S. Molecular characterization of Listeria species isolated from frozen fish. Alexandria J. Vet. Sci. 2014, 40, 1. [CrossRef] 
35. Kaur, S.; Singh, R.; Sran, M.K.; Gill, J.P.S. Molecular characterization of Listeria monocytogenes in white meat samples from Punjab, India. Indian J. Anim. Res. 2018, 52, 1635-1641. [CrossRef]

36. Soni, D.K.; Dubey, S.K. Phylogenetic analysis of the Listeria monocytogenes based on sequencing of $16 S$ rRNA and hlyA genes. Mol. Biol. Rep. 2014, 41, 8219-8229. [CrossRef] [PubMed]

37. Soni, D.K.; Singh, M.; Singh, D.V.; Dubey, S.K. Virulence and genotypic characterization of Listeria monocytogenes isolated from vegetable and soil samples. BMC Microbiol. 2014, 14, 241. [CrossRef]

38. CFSPH. Listeriosis; The Centre for Food Security and Public Health, Iowa State University, College of Veterinary Medicine: Ames, IA, USA, 2019; pp. 1-12. 